PEDAG O G I A E H I S TOR I A

\title{
Apuntes sobre procesos socioculturales y enseñanza de la literatura en América Latina entre 1940-1990
}

William Fernando Torres Especialización en Conunicación y Creatividad para la Docencia

\section{Dependencia y urbanización (1940-1960)}

En los avatares de la Guerra Civil Española, la II Guerra Mundial y la Guerra Fría, los paises de América Latina asistieron al acontecer internacional siempre en curiosos papeles marginales: en la primera, aportaron militantes para la causa republicana y recibieron perseguidos políticos y emigrantes; en la segunda, proveyeron de ciertas materias primas a los países aliados y, de manera tímida, le declararon la guerra al Eje cuando Estados Unidos, por intermedio de la Unión Panamericana, sugirió la conveniencia de esa actitud; en la tercera, algún pais aportó soldados para enfrentar al comunismo en Corea.

Estos papeles marginales permiten inferir algunos de los procesos políticos y económicos que vivia el continente: brotes de republicanismo y socialismo, por un lado, y dependencia económica y alianza ideológica militar con Estados Unidos, por otro, luego de décadas de sometimiento al capital inglés.

En política, las anteriores circunstancias se advierten en las formas de gobierno imperantes en las diferentes naciones: en unas, endebles democracias, en otras viejas dictaduras. En economía, en ambas se desarrollaban procesos preindustriales o en tránsito hacia la industria liviana: en los campos, la depreciación de los monocultivos, en las ciudades, el crecimiento de pequeñas industrias. Y encima de todo, la presencia del capital extranjero - en particular norteamericano - que quería sacar buenos dividendos de tierras aptas, matcrias primas y mano de obra barata y leyes y autoridades complacientes (1).

El bajo precio de las cosechas arrojó numerosos grupos de campesinos a las urbes tras la ilusión de los empleos que creaba la industria. En consecuencia, las ciudades tuvieron villas miserias en Buenos Aires, favelas en Río, callampas en Santiago, barrios nuevos en Lima, tugurios en Bogotá para los inmigrantes; pero también fábricas, barrios obreros, salones de baile, bares, emisoras radiofónicas y cines, tanto para los campesinos como para quienes habían conseguido empleo en la industria. Como es natural, alli aparecieron estilos 


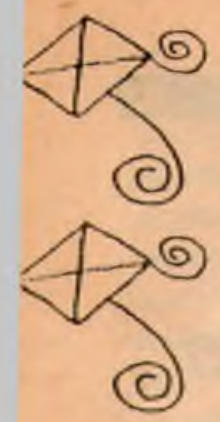

le vida que combinaban el sentido comunitario del campo y el individualismo y anonimato de la ciudad, lo tradicional y lo moderno, el amor machista y el cortesano, lo popular y, en algunos casos, la aspiración a lo culto.

Junto a ellos, fueron ensanchándose los estratos medios urbanos en barrios perifiricos de casas iguales que, como sus habitantes, imitaban los modelos y la distincion de la high. Las oligarquias criollas, a su vez, abandonaron sus antiguos territorios en el centro de las ciudades y se refugiaron en exclusivos barrios que construyeron a las afueras. Estos sectores sociales, concehi. .. la cultura como el dominio y disfrute de las bellas artes y la literatura para obtener, además, distinción social. No obstante, entre ellos hubo las eternas excepciones a la regla: unos cuantos populistas (2).

En medio de estos procesos de nueva dependencia y urbanización, la cultura oral mantuvo su papel integrador de los sectores populares. Pues sobrevivieron y se mestizaron las maneras de explicar el mundo implícitas en las tradiciones orales. En su urdimbre estaba entretejida la doctrina de los dioses aborigenes pero también la de los católicos, los espantos y aparecidos y las nuevas y recelosas experiencias de la ciudad. Y a su lado, las noticias e ideas transmitidas por la cultura letrada en los periódicos fueron leidas en voz alta para posibilitar la asociación de lo local y cotidiano con lo que ocurría más allá del paisaje conocido.

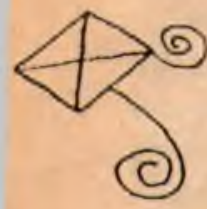

Asi mismo, los miembros de las culturas orales tuvieron acceso a la letrada por medio de la literatura de cordel, almanaques agrarios, novenas religiosas, libros de cartas de amor, fotonovelas seriadas sobre héroes justicieros o asuntos del corazón (3).

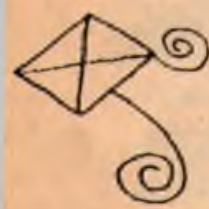

Por su parte, los sectores más consolidados de las clases medias apostaron a la cultura letrada. "Saber es poder" era su lema. Asi se hicieron a lecturas y maneras de salón que les ayudaron a conseguir plazas en los puestos públicos. Pese a ello, las prédicas anarquistas y socialistas influyeron en algunos de sus miembros.

Entre ellos había una buena parte de la intelectualidad. Empero, todavía no

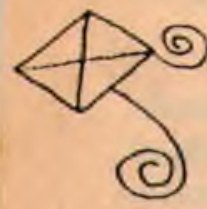
eran profesionales de su oficio: no podian vivir de sus libros, trabajaban en publicidad o en periódicos que, por cierto, ahora llegaban a grupos más numerosos. Las editoriales eran pequeñas empresas culturales que, andando el tiempo, iban a cumplir una tarea significativa en la divulgación de los clásicos de la literatura y la política entre los estratos medios (4).

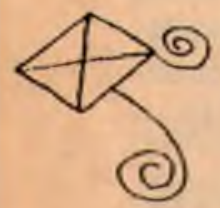

A su vez, en la cultura audiovisual, la radio y el cine contribuyeron a la transformación del sentimentario y el imaginario de las nuevas masas. La primera, difundiendo radionovelas que revelaban cuánto estaban cambiando los valores afectivos o transmitiendo las músicas más a cogidas por los sectores populares, como el tango, el bolero y la ranchera, que en sus letras expresaban los traumatismos que vivían los recién llegados a la urbe, la añoranza del lugar natal y de la madre o los conflictos del amor tanto con la mujer idealizada como con la esquiva o la prostituta (5). El segundo, el cine, le fue descubriendo a los latinoamericanos su propio paisaje y unos héroes o cómicos con quienes identificarse (6). 
Ante este panorama, en la mayoría de países, la educación se debatió entre ser religiosa y privada o laica y oficial. En ambos casos, estaba dirigida a formar los cuadros de los estratos altos y medios para dirigir el Estado y la empresa privada.

Al interior de aquella, la literatura era la materia que tenía como propósito difundir la noción imperante de cultura $y$, dentro de él, cultivar - valga la redundancia-- el buen decir, como a la sazón se llamaba a la expresión correcta y elocuente.

Su enseñanza, en las primeras décadas del siglo había contribuido a la sacralización de los poetas, a convertirlos en estrellas públicas, al obligar a aprender de memoria sus versos para que fueran difundidos por uno de los medios más populares de la cultura oral: la declamación. Así mismo, había propuesto como métodos de análisis literario el biográfico - leer a partir de examinar la vida del autor-y el impresionista - valorar los textos con base en las emociones que suscitan-. En las décadas que nos ocupan y gracias al asentamiento de profesores españoles en Buenos Aires, a finales de los 30, pasó a formar en el hábito de la lectura a los estudiantes, a dotarlos de una cultura del libro y, a la vez, a entregarles algunos elementos -estilísticos, en especial-para el análisis del mismo (7). La crítica literaria, por su parte, tenía apenas un pequeño lugar en la prensa.

\section{Modernización y masificación (1960-1990)}

A partir de 1960, con el triunfo de la Revolución Cubana, América Latina comenzó a ser mirada en la escena internacional de manera diferente a como lo había sido hasta entonces: no como un lejano territorio en el que cada tarde ocurrían revueltas, sino como un lugar en donde se iniciaban procesos políticos novedosos e interesantes.

En efecto. Se vivía, por un lado, la modernización de los aparatos de gobierno propuesta por la Comisión Económica para la América Latina y exigida por organismos internacionales; por otro, se percibía el crecimiento de la industria, la economía extractiva y, por supuesto, de las ciudades. En su interior se expresaba la efervescencia de las nuevas clases medias urbanas que habian conseguido sus títulos universitarios, creaban partidos de izquierdas o formaban guerrillas rurales y urbanas. También aparećan con mayor vigor los ejércitos de proletarios y desempleados que contribuían a consolidar la masificación de las urbes. Estos procesos enmarcaron la experiencia socialista chilena a partir de 1973 y la llegada al poder de los sandinistas en Nicaragua en 1979.

A la par de estos tránsitos, aparecieron otros actores. En los países andinos, surgieron los narcotraficantes que provenían con frecuencia de campesinos desplazados a la ciudad y que introdujeron nuevas formas económicas, mentalidades y maneras de legitimación social.

Sin embargo, la caída de Allende en Chile, el resurgimiento de las cruentas dictaduras militares en el sur y centroamérica, empujaron a miles de latinoamericanos al exilio o a convertirse en inmigrantes en México, España, Alerhania, Suecia, entre otros. Estos hechos, por consiguiente, llevaron a la conclusión de que
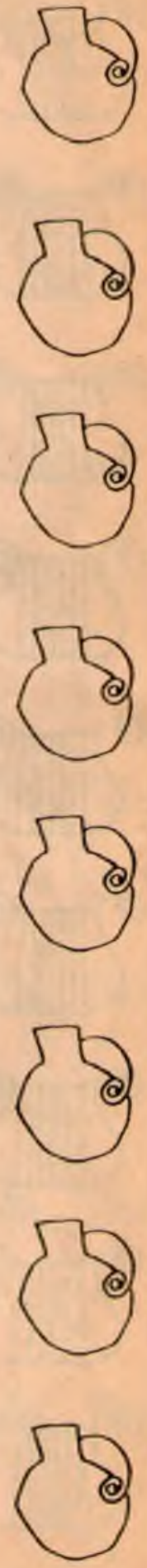

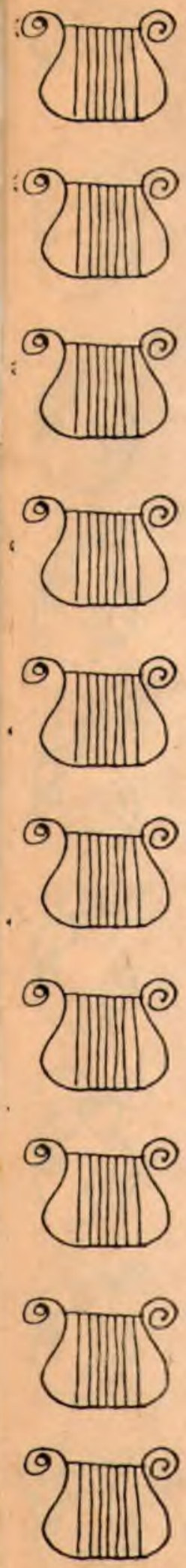

Latinoamérica habia dejado de ser el laboratorio político del planeta. En los 80, cll medio de los experimentos neoliberales de sus gobernantes, el continente debió aceptar que no era otra cosa que uno más del club de deudores morosos de la banca internacional.

En suma, en el curso de estas tres últimas décadas las miradas sobre cstas lierrats pasaron del interés por sus procesos, a la protesta internacional contra las dictaduras, la solidaridad con los perseguidos políticos y el rechazo a los emigrantes.

Los anteriores trazos evidencian que América Latina tuvo un traumático ingreso a la modernización capitalista. Por tanto, en los últimos treinta años fueron muchas las certezas que se tambalearon (y continúan tambaléándose) en la política, la economía, la sociedad, las culturas.

Como es de suponerse, los tambaleos y transformaciones en el caso de las culturas se advierten a primera vista. Las culturas orales, por ejemplo, se urbanizaron. Mantuvieron su socarronería y a ella sumaron un corrosivo humor que hacía chistes sobre políticos y poderosos y se burlaba de sermones y discursos. Estas oralidades - la una popular, la otra oficial-, se disputaron espacios en la radio y lucgo en la televisión. En estos medios, la oralidad popular se expresó en los programas radiales para las audiencias campesinas al amanecer o en los humorísticos, también en las series y melodramas televisivos, que hicieron un rápido recorrido desde el culebrón hasta las telenovelas que destacaban las particularidades regionales o la vida de las clases medias y populares urbanas metropolitanas. Pero esta oralidad fue más allá: se apropió de algunos aparatos tecnológicos para producir su propio discurso, sus propias radionovelas en los barrios perisféricos y en el campo (8).

La oralidad también permeó la cultura letrada. Primero, en los diálogos costumbristas de algunos escritores que se atrevicron a romper con las rígidas normas académicas; más tarde, en los lenguajes coloquiales urbanos que los escritores llevaron a la narrativa y, después, los poetas a sus versos. Por último, en ese género que hizo rápida carrera en América Latina: el testimonio. Este se utilizó, a la manera de las historias de vida acostumbradas en las ciencias sociales, para entrevistar a familias pobres de México, a cimarrones cubanos, a campesinos, a sicarios, etc., y dar cuenta de quienes no habian sido protagonistas de procesos $y$ hechos trascendentales. Por este camino, pronto se llegó a la historia oral. (9)

Las culturas audiovisuales fueron asentándose en la región desde los 50 , pero sólo comenzaron a llegar a sectores de la población cada vez más amplios en la medida en que los aparatos fueron más portátiles y privados y estuvicron al alcance de todos los bolsillos: la radio de salón, el gramófono y el tragaperras dieron paso al transistor y este al walkınan; la televisión en blanco y negro cedió ante el avance de la a color, el video, los juegos electrónicos. Además, se difundicron canales internacionales que con sus nuevas lógicas y nociones del tiempo transformaron de modo radical las de las culturas que venimos reseñando.

Igual ocurrió con la música: al tango, el bolero y la ranchera, aunque mantuvieron sus adeptos, dejaron paso al rock, las baladas y las músicas caribes 
- como la salsa - que expresaban la presencia de unas juventudes poco tenidas antes en cuenta y que ponían sobre la mesa nuevas nociones del mundo, la autoridad, el amor, el sexo, la vida cotidiana. Como ha dicho Antonio Cándido, en América Latina se dió un salto de la cultura oral a la audiovisual sin pasar por la escrita. (10)

Esta última, a su vez, se vió fortalecida por el surgimiento o la consolidación de editoriales que salieron a la calle a ampliar sus mercados como en los casos del Fondo de Cultura Económica, en México, o de Eudeba, en Buenos Aires.

Los narradores, por su lado, reemplazaron a los poetas en el altar de la veneración literaria. Este proceso se inició con los reconocimientos que alcanzaron las obras de José Eustasio Rivera y Horacio Quiroga y que comenzaron a opacar la fama continental de Ruben Darío. A tal punto se llegó en él que al morir Quiroga se le rindió en Montevideo un homenaje tan multitudinario como no los habían tenido Rodó, Florencio Sánchez ni Zorrilla de San Martín (11).

Pero quienes usufructuaron estos antecedentes fueron los narradores de los 60 que tuvieron una difusión masiva tanto en América Latina como en traducciones en Europa y América del Norte. Quizá su éxito se deba a dos razones: la primera, porque sus vidas tenían el encanto de la aventura lograda, en la que por amor a una vocación testaruda pasaron duros trabajos en el mítico París de los 50 , sobrevivieron en oficios no considerados sacros como los de redactores y comentaristas para la radio, creativos en agencias de publicidad, guionistas frustrados, traductores; la segunda, porque sus obras rompieron con la tradición literaria realista para incorporar lo mágico, lo onírico, lo simbólico, nuevas formas de composición, nuevos lenguajes. Es decir, estas obras hablaban a nuevas camadas de lectores, a esas que tal vez los autores habían intuido y conocido en sus oficios para la sobrevivencia (12).

Pero los procesos de América requerían no sólo las iluminaciones de la literatura sino también las explicaciones de las ciencias sociales. Estas se elaboraron en facultades creadas o reformadas a lo largo de los 50 y principios de los 60 en Buenos Aires, Sao Paulo, México y Bogotá, entre otras. A ellas llegaron profesores europeos que expusieron las nuevas corrientes teóricas en economía, antropología, sociología, comunicación, al introducir los desarrollos del marxismo, el estructuralismo, las tendencias psicoanalíticas, la semiótica, la teoría crítica.

Ellas permitieron ir reelaborando reflexiones propias y construyendo propuestas para atender las urgencias del continente. A la luz de esos a portes, en largos debates, se discutió sobre la caracterización socioeconómica de este - si era colonia o neocolonia, feudal o capitalista - , sobre su cultura - si existía o no una cultura latinoamericana -, sobre el papel de los intelectuales. De allí nacieron, por ejemplo, en lo militar, la teoría del foco guerrillero; en economía, la teoria de la dependencia y la del desarrollo a escala humana; en educación, la pedagogía del oprimido y la educación popular; en investigación, la acción participativa; en religión y filosofía, la teología de la liberación y la llamada filosofía latinoamericana. Hubo, además, desarrollos en la investigación en comunicación que se dedicó, primero, a desentrañar las propuestas ideológicas implicitas en los mensajes
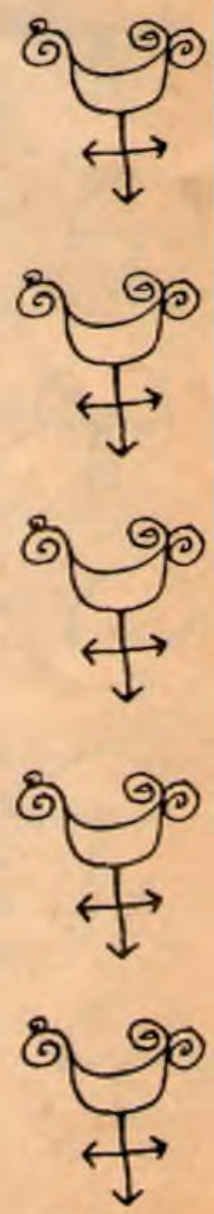
producción, su paisaje, su vida cotidiana, las mentalidades, en tan sólo medio siglo. En ella, las culturas orales mayoritarias se entrecruzan con las escritas y las audiovisuales $y$, en conjunto, se caracterizan como culturas híbridas en las que existen elementos de la modernidad y la postmodernidad. La cultura escrita ha servido para formar a las élites pero también para dar cuenta de las particularidades del continente. Su enseñanza y la de las producciones literarias sin embargo, ha estado influida/desviada por las lógicas de la cultura oral y culturas populares y, durante la dos últimas décadas, cuestionada por el avance audiovisual.

\section{NOTAS}

(1) Halperin Donghi, Tulio (1969). Histeria contemooránea de América Latina. Madrid: Allanza editorial, p. 359 y ss.

(2) Romero, José Luis (1976). Latinoamérica: las cludades v las ideas. Buenos Aires: Siglo XXI Argentina Editores, p. 319 y ss.

(3) Sobre la lectura en voz alta y la relación de los analfabelas con la cultura escrita, ver: Chartier, Roger (1992). El munde come representación. Barcelona: Gedisa, p. 107 y ss.

(4) Gutiérrez Girardot, Rafael (1990). Iemas y oroblemas de una historia social de la literatura hispaneamericana. Bogotá: Cave canem, y además, Angel Rama (1980). "El boom en perspectivan en (1992). La novela latineamericana 1920-1980. Bogotá, Procultura/Colcultura.

(5) Monsiváis, Carlos (1977). Amor oerdido. México: Biblioteca Era, p. 61 y ss.

(6) Martín Barbero. Jesús. (1987). Delosmediosalas mediaciones. México: Gustavo Gili, Capítulo 3.

(7) Goic, Cedomil (1988). Historiavcrítica de la literatura hispanoamericana. Enoca contemooránea Barcelona: Editorial Crítica, p. 31.

(8) Alfaro, Rosa Maria (1989). De la conquista de la ciudad a la zorooiación de la palabra. Lima: Calandria.

(9) Ver mi artículo "Conversar bajo el almendro" en Francisco Garzón (1991). El arte escénico de centar cuentos. Madrid: Editorial Frakson, p. 151 y s.s.

(10) Cándido, Antonio (1972). "Literatura y subdesarrollo" en Alfredo Chacón (1975). Cultura y dependencia. Caracas: Monteávila.

(11) Véase la cronologia biográfica preparada por Oscar Massola para el libro de Noé Jitrik (1959). Horacio Quiroga, Montevideo: Arca, 1966.

(12) Rama, Angel. Op. cil., p. 271 y ss

(13) Véanse los libros del ya mencionado Jesús Martín-Barbero Discurso v poder (Quito: Ciespal, 1981), Itinerarie oara salir de la razón dualista (México: Gill, 1981) y Lelevlsión y melodrama (Santafé de Bogotá: Tercer mundo, 1992), y, además, los de Néstor Garcia Canclinl Las culturas pepulares en el capltalismo (La Habana: Casa de las Américas, 1981), Las políticas culturales en América (México: Grijalbo, 1987) y Culturas hibridas. Estrateglas para ontrac y sall de la modernidad (México: Grijalbo, 1990).

(14) Fernández Retamar, Roberto (1972). Calibán. La Habana: Casa de las Américas. 